\title{
ON THE SEDUCTIVE LIGHTNESS OF BEING: INSIGHTS INTO CYBERSPACE
}

\author{
Julia Fauth \\ Coordinator for Youth Interaction, International Council for Caring Communities, and MA \\ Student, London School of Economics
}

Abstract: $\quad$ Since the 1980s, the continuing developments, changes and hybridisations in information and communication technologies have essentially influenced our ways of perceiving, thinking and behaving. The media revolution in the Internet Age affects all areas of our society. Today we are living far beyond McLuhan's Gutenberg Galaxy, but nevertheless we can see the points of reference for at least structural comparisons between both phenomena - that of the Internet revolution and that of the emergence of printing. In addition to "place-centric" knowledge perspectives, historical approaches also seem not only possible, but also necessary. The present paper offers a thought project for a kind of macro-philosophy of media, which could be defined as a reflective consideration of global media praxis and media politics, and thus a media ethics with a claim to global validity. Such a thought-project could fill a gap in the scientific discourse on media, which cannot be tackled so broadly by using the differentiated concepts surrounding the "Global Village", which were developed from sociological and macro- or micro-economic perspectives.

\section{BEYOND POST-MODERNITY}

\subsection{An Unprecedented Generation of Internet Users}

In a recent article in a well-known computer magazine, a commentary was provided on an development, which is both socially and economically interesting, in South Korea, where e-mail is slowly but surely becoming "snail mail". South Korean teenagers are obviously some way beyond the 
average users of modern telecommunications offerings and thus the best examples of "earliest adopters"; they are consumers in the Information Age par excellence.

The teenagers said that they now only used e-mail when they wanted to communicate with older people. Otherwise they only used Instant Messenger, or mini-Homepages, or Internet blogs, for fast communication.

What realities are coming together here? In a world where 80 percent of the population does not even have access to communications devices like fixed or mobile phones, the post-post-modern communications consumers no longer deal in seconds, but in milliseconds. Obviously, this raises key issues that are not only economic and infrastructural in nature, but also social and ethical. But, along with questions of equal treatment and equal rights in the context of globalization, when one reads about such phenomena as only the Internet Age can bring about, the question arises as to what kind of world view (or world views) are we going to leave behind with this rapid pace of communications, and towards what kind of new views are we moving?

\subsection{A Thousand and One Approaches to the Media Revolution - Which is the Right One?}

The problem areas arising in the media revolution in the broader context of globalization are spread across various branches of knowledge, from macroeconomics, sociology and on to philosophy. The media revolution in the Internet Age affects all areas of our society. To echo Niklas Luhmann, it integrally penetrates and modifies every single subsystem in our society, whether it is agriculture, culture or politics, with an intensity that can only be compared with the invention of printing and its consequences on trade, culture and science.

Today we are living far beyond the Gutenberg Galaxy (McLuhan, 1986) of yore but nevertheless we can see the points of reference for at least structural comparisons between both phenomena - that of the Internet revolution and that of the emergence of printing. In addition to "placecentric" knowledge perspectives, historical approaches also seem not only possible, but also necessary.

This thought project of a kind of macro-philosophy of media could fill a gap in the scientific discourse on media, which cannot be tackled so broadly by using the differentiated concepts surrounding the "Global Village", which 
were developed from sociological and macro- or micro-economic perspectives.

\subsection{Introducing the Thought Project of a "Macro- Philosophy of Media"}

A macro-philosophy of media could be defined as a reflective consideration of global media praxis and media politics, and thus a media ethics with a claim to global validity. In the discourse to date, relatively little significance has ever been attributed to this in orthodox philosophy, let alone the comparatively young branch of media studies.

This is a gap that should not be underestimated: When modern communications media are accessed through global networks, what has happened and happens is always in the framework of the communications and media politics of the various nations or of the private sector operating with the gold rush mentality of the "New Economy". Both are areas that offer notoriously little space for media-ethical questions.

Thus, the example of the South Korean teenagers highlights the need to develop new perspectives and approaches to the "Global Village" and its largest knowledge resource, the Internet, that include the amazing performers of the internet generation themselves. The youth as earliest adopters and fastest users of information technologies could provide perspectives in a dialogue on global media that would open spaces to ask the questions and pose the problems which the New Economy would prefer to leave unaddressed.

Phenomena like the South Korean teenagers and their relationship to communications should not be seen in isolation, but in the context of a world which is certainly not universally networked. This encourages us to look at such examples, which lead us deeper and deeper into cyberspace, in the search for new categories for space, time and human identity.

A macro-philosophy of media would address precisely such problems. It would take as its theme not the New Economy, but the people in the New Economy, the "digital consumers", the people of the Information Age and equally those on the other side - the people who are excluded from looking into cyberspace - and that is the majority of the world.

A macro-philosophy of media would be equivalent to a humane and ethically driven look into cyberspace. 


\section{MAN AND MEDIA}

The media-focused world parades in front of us every day, consisting of many different geographical, political and economical dimensions. Just as the ambivalence of our economic description certainly increases, the more conventional description criteria fail. So it is up to us to find new description criteria. We have to facilitate a discourse on nothing less than us and the media.

Naturally there are already forums in which such a discourse is under way, but these are mostly discussion spaces operating in the traditional culture- and social-critical way, as literature, but without a direct approach to political praxis.

The Norwegian author Jostein Gaarder has been conducting a mediaphilosophical discourse since the beginning of the nineties through his works of fiction: "The Time Scanner" (Gaarder, 1997) is one of his literary future dystopias, which cleverly show where the actual problems of cyberspace lie, or to put it better, could lie, when it eventually really will become commonplace to consider e-mail as snail mail, and to circle the world in record times through the Net.

He considers the kind of human that might exist in the future. In his short story, he depicts the image of humans hundreds of years after us, so networked that every activity away from the computer terminal, which of course every household would own, would be a lapse from the normal form of existence. Time and space are overcome with the help of the groundbreaking developments of quantum physics. A so-called time scanner can measure, and through its display make accessible, every place and every time in the past - with the result that, by taking constant historical cyber tours, the present is no longer created, with the exception of the one that takes place in front of the computer terminal. In the truest sense of the words, history stops. A bold idea.

Gaarder's fictional excursion into the future makes it only too clear which basic categories of human life are suddenly open to discussion and reconstitution, when it comes to the influence of the new media on human life, or rather the constant increase of this influence - an influence which is so profound that, before our very eyes, it revolutionizes the concepts of time, space and work, the basic social and economic determinants of our human coexistence. 
Naturally Gaarder is not the first to conceive of a media-philosophical dystopia. Rather, he takes his place in the tradition of a whole series of thinkers who from the beginning, and in a very targeted way, have reflected with critical distance on the relationship between "Man and Media".

\subsection{The Impact of Media on Social and Political Structures}

Going back more than two thousand years, even in Plato's "По $\lambda \iota \tau \varepsilon 1 \alpha$ ", the Republic (Plato, 1999), there are reflections on the changes in humans and their social and political contexts in the transition from oral to written culture. This critically reflected position on the emergence of new forms of media passes through history schematically and blossoms again as it arrives in the twentieth century with the conquest of television.

In the post-modern era, 2,500 years after Plato, Neil Postman delineated the fundamental influence of television on humanity. Joshua Meyrowitz (1985) even attributed to it true witchcraft in its presentation of social role models. Marshall McLuhan (1995) saw it as the extension of our five senses and the sociologist Pierre Bourdieu (1996) uncompromisingly made the point that "Television has a kind of factual monopoly in the training of the brains of most people: "Television increasingly decides who and what exists, in a social and political sense."

\subsection{Humans of the Internet Age have many faces}

The "Digital Age" has already found its media critics, who try to get to the bottom of what "Being Digital" (Negroponte, 1995) means and explain the radical transformation of the world of atoms to the world of weightless bits - and the demand for explanations is large.

As is now perfectly clear, this transformation has initiated a fundamental recoding of our daily life. But why does the media-critical man in the Media Age address both sides of the mirror so faint-heartedly - himself and technology in a new interdisciplinary domain of understanding?

The changes in our society, our economy and our access to knowledge brought about by digital media should set in motion a discourse that should not be reducible to technical, economic or political aspects of the media revolution. 
Manuel Castells (2003) has performed the best spade-work for such a discourse: with his concept of Network Society he is able to express how greatly the recoding of our daily life in the course of the "Digital Age" has brought technology and society in parallel and how both domains have been networked into a completely new culture of behavioural goals and options.

These do nothing less than bring about a new kind of human being: not the computer-steered cyborg of horror films, but a far subtler and more ambivalent creature, a creature with many faces: that of the Korean highspeed Internet user, as well as that of 80 percent of the earth's inhabitants, who have no access to the instantaneity of the software world. Up to now, this new orientation of humans in the "Digital Age" in a global context of increasing social heterogeneity and discontinuity could not be made completely comprehensible with the individual measuring rods of economic, sociological, philosophical or even media studies thought-models.

To encapsulate this point: even a macro-philosophy of media will not be able to offer a holistically comprehensive approach to "Digital Age" man, although it would be able to analyse the concept in the media context in an as-yet unknown manner and perspective. This is urgently needed in the array of current analytical approaches to digital being.

\subsection{The benefits of a macro-philosophy of media}

This new model of philosophy could address what have seemed up to now fringe events: the permanent data flow of the Information Society and the continual addressability of everyone locked into the global village and its effects on our thinking in the categories of time, space and the basic concept "work", but also the ever-more extreme effects of discrepancies between an networked and an un-networked world.

A macro-philosophy of media would be able to reflect on why the categories of knowledge and information suddenly find themselves in a controversial discussion process in the Internet Age, on one hand being treated as economic resources and on the other, from the perspective of the Information Society, fatally over-valued.

A macro-philosophy of media is bound to ask why knowledge and information couldn't be democratized in the spirit of educational tradition and as a result of its increasing digitization and availability. 
A media-ethical question: since digital technology is capable of facilitating easy access to knowledge and information, shouldn't every human have the right to this information and knowledge?

From this perspective, media are an ethically contentious good, and in a sense reality, which can develop political and economic thought models. The phrase "can develop" is deliberately used here, since we have to accept the notion that basic cultural-historical concepts like knowledge and information in a digital age run through the process of a disengagement of thought models that are drawn from both purely the humanities as well as purely economics and politics. It becomes a challenge to allow the individual fields and disciplines to be considered in an innovative and interdisciplinary discourse and exchange of opinions.

\section{PUTTING MACRO-PHILOSOPHY OF MEDIA INTO PRACTICE}

In order to be able to speak of a global framework, we need to have forums that can bring together the different interest groups of global civil society, the private and governmental sectors, under the umbrella of internationalism, state community and with a basis of principles of democratic agreement.

Macro-economics and the macro-philosophy of media should meet wherever political, economical and social changes can be discussed at a transnational level and where their implementation can be initiated. With such a framework, the macro-philosophy of media will be seen as an essential element within a praxis-oriented media ethics.

To date, only a few international bodies dealing with communication politics have included media philosophy in their proceedings.

As the community of policy negotiators in international communication politics is currently endeavoring to define a new international body which could fill the gap of an open and transparent, globally serving multistakeholder forum on harnessing information and communication technologies for development, all entities which are being included in that transition process should challenge themselves to not only think about the definition of a new shape in which a global discussion forum could be incorporated but rather move towards a thinking in genuine new patterns in order to create an authentically interdisciplinary discourse and 
heterogeneous collaboration of partners in the domain of Information and Communications technologies (ICT) for development.

\subsection{Thinking Communication Policies in New Patterns in an Innovative Forum}

A purely political-economic think-tank can do without media ethics, but a heterogeneous community of interests, envisaged as multi-stakeholder forum of Information and Communications Technologies and their policies cannot, if it seeks to fulfill its decent responsibilities and mandate: to ensure inclusive and transparent discussion about the digital divide, the potential that ICT have for development and the models and ways in which ICT can be harnessed to bridge the digital divide and to make the benefits of the new technologies accessible to all. This includes dealing with the teleological question of where a human in the Digital Age, with the plurality of faces that he now has, can go, and where he wants to go.

As a young citizen of the "Global Village" the present author cannot avoid challenging herself with this question whenever she encounters other young citizens of the Information Age through the Internet using technologies like instant messengers or e-mail. It is still stunning how the new information and communication technologies are able to dispel distances within milliseconds and open unprecedented opportunities for global dialogue and exchange.

Young people, as tireless users and promoters of those new ways of "Communication without Borders" are capable of providing meaningful input to both policy-making and philosophical reflection in the area of ICT. Thus they should be included formally in all discussion processes aimed at creating a new, transparent and inclusive body, a multi-stakeholder forum to advance ICT for development and harness them as a valuable tool for the next generation in particular.

Such a body is going to be further defined within the scope of forthcoming events such as the Summit examining the progress after five years towards achieving the Millennium Development Goals, originally set by Kofi Annan in his Millennium Declaration in 2000, and the ninth meeting of the UN ICT Task Force.

The UN ICT Task Force, established by Kofi Annan on request of the Economic and Social Council in 2002 attempts to add a forum with global reach and extent to the multitude of efforts to bridge the digital divide. The 
Task Force is officially being supported by the Heads of State and Government of all UN member states who endorsed the ECOSOC Ministerial Declaration at the Millennium Summit in 2000.

The Task Force seeks to enhance partnerships between the United Nations system, Governments, the private sector and financing trusts and foundations, donors and programme countries in order to define and develop mechanisms to unleash the potential of ICT as key tool for development.

As the mandate of the UN ICT Task Force ends in December 2005, a vivid discussion has been launched in the ICT for development community about the needs and definitions for possible follow-up models to the Task Force.

The most common vision that has been shared so far favors an inclusive, transparent and in its structure lighter multi-stakeholder forum than the Task Force forum has been. However, those new ideas are being exposed to the different, both critical and supportive views of the various stakeholders in ICT for development.

Remarkably, the discussion process has highlighted less the general aspects which could form a Global Alliance in the best imaginable way for the global community and rather pointed to the political issues which constrain the creation of this new forum on ICT for development.

However, everybody who believes in ICTs and their potential for human development should try to imagine a global forum on ICT which follows the prerequisites of equal access to all stakeholders, of democratic rules and legitimacy.

The following section is a response to three basic ideas which dominated the Global Alliance discussion in the beginning, from the prospective of their relevance to youth:

\subsection{Stronger Linkage between MDGs and ICT}

First of all, the needs for a stronger linkage between the action lines in ICT for development and those declared and identified in the Millennium Development Goals (MDGs) could be fulfilled through a Global Alliance on ICT for development. Such a linkage would address youth as meaningful stakeholders and contributors to effective discussion and policy making in particular. 
Young people around the globe have shown their strong interest and commitment to the fulfilment of the Millennium Development Goals, have strongly engaged themselves in the Millennium Campaign and have contributed with fresh ideas to the Millennium project as students or members of youth organizations. Furthermore, they have already implemented such a required linkage between the MDGs and ICT for development in communities like the World Summit on Information Society Youth Caucus. Members of the Youth Caucus have contributed to the Millennium Project and the Millennium Campaign, were members of the ad hoc working group for youth and the MDGs, but have also actively been involved in the World Summit on Information Society and the Global Forum of the UN ICT Task Force.

Against this background, youth participation should be warmly welcomed both in the Global Alliance and in events around the MDG + 5 that are going to deal with ICT as tool for implementing the MDGs.

How fruitful such an inclusion of young people can be, has become clear at the recently held eighth meeting of the UN ICT Task Force where the Youth Caucus of the World Summit on Information Society had been asked to officially intervene and interact with other stakeholders of the ICT for development domain in the UN ICT Task Force forum. Given the success of youth interventions in the preparatory stages and first leg of the World Summit on Information Society, the involvement of youth in the Task Force forum has been considered as being both unprecedented and indispensable for future discussion processes on ICTs for development.

A frequent criticism voiced in the World Summit on Information Society process is that the private sector has only been insufficiently involved in the ICT for development agenda. However, where interaction between private sector and civil society has proven to be particularly beneficial to the development aspect of ICT, was when it occurred between youth and the private sector: in the form of sponsorships for youth projects, campaigns or youth discussions. The private sector has supported the inclusion of young people in ICT for development and this activity should be even further enhanced. Young people are both a repository of creativity and idealism when it comes to the new technologies of the information age and the group of earliest adopters and consumers of ICT. These facts should define new action lines in the private sector when it comes to youth and ICT. The private sector is being asked increasingly to recognize the financial as well as the social potential which lies in its interaction with the youth sector. To perceive youth as one of the most lucrative groups of consumers should at the same time lead the private industry to undertake a decent commitment to 
empower youth not only as consumers but also as social entrepreneurs, youth activists in development and by doing so enhance the idea of human development and shared social responsibility among the generations.

\subsection{Intergenerational Dialogue}

South Korean youth provide the best example of the needs for intergenerational dialogue. As the fastest adopters of ICT, they provide hoards of experience and thinking that are different from the former generation. Clearly, this should be the best argument to share those different experiences and approaches in an intergenerational dialogue and by doing so move on to a decent understanding of social coherence and integration. This should not be only a prerequisite for the Global Alliance but for all community driven bodies, whether they act on a local or global level.

\section{CONCLUSION}

The inclusion of youth in the yet-to-be-established Global Alliance has to begin in the phase of its definition. Young people can be seen as meaningful contributors to linkages and bridges between ICT and MDGs. Consequently, youth stakeholders need to be empowered so that they can fully and formally participate in that process to make their voices have that impact they deserve.

\section{REFERENCES}

Bourdieu, Pierre (1996): Sur la télévision. Paris: Raisons d'Agir.

Castells, Manuel (2003): Das Informationszeitalter. Wirtschaft - Gesellschaft - Kultur. Band I-III. Stuttgart.

Gaarder, Jostein (1997): "The Timescannet" and "Arbitrary Consciousness". In: A Rare Bird. German Translation. Munich.

McLuhan, Marshall (1986): The Gutenberg Galaxy. The Making of Typographic Man. Toronto: University of Toronto

McLuhan, Marshall (1995): The Magic Channels. Understanding Media. Dresden. Verlag der Kunst.

Meyrowitz, Joshua (1985): "No Sense of Place": The Impact of Electronic Media on Social Behavior. Oxford.

Negroponte, Nicholas P. (1995): „Being Digital”. New York. Toronto. Random House.

Plato: The Republic. Leipzig, Reclam. 1999. 